\title{
THE COSMOPOLITAN GOAL (IDEAL?) OF COMPARATIVE LAW: REASSESSING THE CORNELL COMMON CORE PROJECT
}

\author{
Siyi Huang ${ }^{*}$
}

\begin{abstract}
Comparatists do not ordinarily recognize the fact that the debates on comparative legal methodologies are always centered on how to understand other legal systems. Partial and parochial views contained in existing comparative studies reveal that comparativists should have a cosmopolitan goal, which means to avoid biases and partialities when they examines legal systems from their own perspectives. The Cornell Common Core Project, carried out in the 1960s at Cornell Law School, serves as an excellent example of how comparative legal studies could pursue the cosmopolitan goal. The factual method and the teamwork method employed by the Cornell Common Core Project are effective in preventing individual perspectives from distorting the images of legal systems under consideration. Nevertheless, the Project has shortfalls in its methodology, because the teamwork method incurs 'internal biases' and the leader of the Project, i.e., Rudolf Schlesinger, is an advocate for 'searching similarities'. The conception of cosmopolitanism also faces the danger of being misinterpreted into legal 'eschatology'. In spite of these limitations and danger, a new development in comparative legal methodology can be found to be currently in progress at Cornell Law School.
\end{abstract}

\section{Introduction}

In essence, debates on methodology in comparative law are always centered on how to understand different legal systems. Regardless of those heavily debated questions, such as whether comparative law should aim at searching for differences or similarities across various legal systems, or whether comparatists should apply local or global legal norms in their legal studies, what is really at stake is the problem of understanding. On the one hand, the focus of comparative law is constantly swinging between searching for similarities and differences. ${ }^{1}$ On the other hand, comparatists at times advocate for 'localism'

* JSD Candidate, Cornell University Law School

1 See Rudolf B Schlesinger, 'The Past and Future of Comparative Law' (1995) 43 AJCL 477, 477-88; See also: Alan Watson, 'Legal Transplants and European Private Law' (2000) 4.4 Electronic J of Comp L VII <http://www.ejcl.org/ejcl/44/44-2.html> [accessed 9 March 2014].

Copyright $\odot$ the Author(s).

This work is licensed under a Creative Commons Attribution-NonCommercial-NoDerivs 3.0 License. 
as opposed to 'universalism' (or vice versa) in the analysis of comparative law. ${ }^{2}$ Nevertheless, both questions revolve around the problem of understanding, i.e., to what extent can comparatists sufficiently comprehend another legal system and how. For example, Weber contended that understanding, or verstehen, was the proper way of studying social phenomena. He thinks that the essence of social inquiries is to understand the meanings that human beings attribute to their experiences, interactions and actions. Pierre Legrand incorporated the problem of understanding in his analysis on the nature of comparative legal scholarship. He writes, "[w] henever somebody sets out the advantages or utility of comparative law, one of those listed is that comparison gives you a different view of your own legal system and this leads to a better understanding. ${ }^{3}$

The same holds true in other comparative studies. For example, according to Bendix, Suchman and Ossowski, 'comparative sociological studies represent an attempt to develop concepts and generalizations at a level between what is true of all societies and what is true of one society at one point in time and space.4 In On The Logic of Comparative Social Inquiries, Adam Przeworski and Henry Teune conclude that the goal of comparative social studies is to establish both 'idiographic' and 'nomothetic' approaches to social science. ${ }^{5}$ Regardless of whether it is 'to develop concepts and generalisations', or to establish 'idiographic' and 'nomothetic' approaches to social science', the foremost problem underlying the same assertions is always one about understanding.

As understanding is so crucial for any comparative study, comparativists have made great efforts to develop methodologies they find most useful to further their understanding. For example, Pierre Legrand employs the anthropological term of 'thick understanding', and argues that comparatists, who want to study a foreign legal system, should strive to develop an understanding of that system at a thick and deep level, i.e. to make better sense 'of the whole. 6 In Comparatists and Sociology, Roger Cotterrell explicates this conception. He writes:

[C]ommunication or comparison demand what anthropologists call 'thick description'- rich, multilayered and detailed accounts of

\footnotetext{
2 See e.g. Imre Zajtay, 'Aims and Methods of Comparative Law' (1974) 7 Comp \& Int'l LJ S Afr 321, 323; John Merryman, 'On the Convergence (and Divergence) of the Civil Law and the Common Law' (1981) 17 Stanford JIL 357, 387; Pierre Legrand, 'John Henry Merryman and Comparative Legal Studies: A Dialogue' (1999) 47 AJCL 3, 47.

3 Ibid, 55 (emphasis added).

${ }^{4}$ A Przeworski \& H Teune, The Logic of Comparative Social Inquiries (1970) 8-9.

${ }^{5}$ Ibid.

${ }^{6}$ Ibid, $40,52$.
} 
social experience to convey complexity of cultural difference, to identify points of empathy and thereby to provide some keys of entry into the understanding and appreciation of different cultures.?

Professor Vivian Curran refers to the method of 'immersion comparison', which carries a similar meaning. Pierre Legrand 'appears to believe that legal philosophy is the key to understanding law in society.' Alan Watson rejects Pierre Lagrand's approach and characterises it as old-fashioned; instead, he advocates the method of 'comparative legal history.' ${ }^{10}$ Despite having famously disparaged comparatists for their relentless search for proper methodologies, Zweigert and Kort developed a 'functional method' to comparative law. ${ }^{11}$ The list goes on.

Building on existing theories on methodology, and consistent with them, this paper argues that the essence of comparative legal studies is always to acquire deep and genuine understanding of different legal systems by overcoming the barriers of cultural differences, while still keeping our understanding undistorted by individual lenses. That is to say, comparative law should have a cosmopolitan goal, according to which comparatists need to eliminate biased and prejudiced views and to make genuine understanding of a legal system different than their own as much as possible. ${ }^{2}$ Genuine understanding, which I will argue must be obtained through a fusion of feelings with scenes, is, therefore, the prerequisite of comparison and analysis.

Nevertheless, the idea of cosmopolitanism in comparative law is not novel. In fact, early Greek and Roman philosophers created the notion of cosmopolitanism in vision of a global community. But it was not until Immanuel Kant that this idea was applied to comparative law, and thereafter it was constantly applied in comparative studies through methodological tools supplied by sociologists. However, the cosmopolitan goal of comparative law is not always explicit; in fact,

7 R Cotterrell, 'Comparatists and Sociology', in P Legrand \& R Munday (eds), Comparative Legal Studies: Traditions and Transitions (2003) 131, 151.

${ }^{8}$ See generally: V G Curran, Comparative Law: An Introduction (2002).

9 See Watson, above $\mathrm{n} 1$.

${ }^{10}$ See generally: Alan Watson, Legal Transplants: An Approach to Comparative Law (1974).

${ }^{11}$ See generally: K Zweigert \& H Kört, An Introduction of Comparative Law (rev edn, 1998).

${ }^{12}$ However, by specifying the cosmopolitan goal of comparative law, I do not intend to conceal or negate the limits of human cognition and the impossibilities of attaining perfection; I do intend to say that the cosmopolitan goal is inherent in the mission of comparative law, and comparatists should always strive for it, regardless of how distant their studies are from this goal. Thus, instead of 'goal', it might be more accurate to phrase this idea as the 'ideal' of comparative law. But, after considering that the word 'ideal' sounds too unrealistic, I decided to primarily use 'goal'. 
what remains at a more visible level of modern comparative law is the concept of rationality. ${ }^{13}$ The relationship of the cosmopolitanism goal, or ideal, to rationality can be described in the same way that Professor Annelise Riles explains the latter. Riles writes ' $[\mathrm{i}] \mathrm{t}$ is the rationality of the comparison [...] that overcomes the particularity of the comparativist's perspective on such a contentious issue ${ }^{14}$, and 'comparative law cannot exist, that is, it cannot work, without this idea (rationality). ${ }^{15}$ In terms of overcoming prejudices and individuality, the concept of cosmopolitanism and that of rationality are functionally equivalent.

However, even the notion of rationality does not completely free comparatists from biases and prejudice. Eliminating them means to resist subjectivity and personality, since the aim is to learn how other people think of themselves, and not to be informed about the researchers' own views. But, as Max Horkheimer's critical distinction between 'objective' and 'subjective' reasons suggests, 'subjective reason [...] limits itself to the determination of the efficiency of means in their relation to ends not themselves capable of rational judgment or justification'. ${ }^{16}$ Therefore, as the notion of rationality fails on its end to overcome prejudice, it is better for comparatists to remove the deceiving mask of 'rationality' and elucidate the cosmopolitan goal of their discipline.

The Cornell Common Core Project was undertaken at Cornell Law School in the 1960s under the leadership of Professor Rudolf B Schlesinger. The aim of this project was to discover if there is a common essence to the world's major legal systems. Contracts law was chosen to be the subject of the project. The project is seen as an ambitious one in the history of comparative law due to the wide range of legal systems it covered and a large international group of legal scholars it engaged. Nevertheless, the project's theoretical position in comparative law remains somewhat under-discussed, and the methodological importance of it is not fully disclosed.

The paper points out that in fact, the Cornell Common Core Project deserves higher esteem in the field of comparative law, given its high degree of adherence to the cosmopolitan goal/ideal of comparative law, which is rarely seen in other previous comparative studies. This is why the paper attempts to re-evaluate the Project and its attainment of the cosmopolitan goal.

\footnotetext{
${ }^{13}$ See A Riles, 'Introduction', in A Riles (ed), Rethinking The Masters of Comparative Law (2001) 1, 15 (emphasis added).

${ }^{14}$ Ibid, 16 .

${ }^{15}$ Ibid.

${ }^{16}$ Arthur E Murphy, 'Review of Book: Eclipse of Reason by Max Horkheimer' (1948) 57 The Philosophical Review 190, 190-1.
} 
Such an adherence to the cosmopolitan goal of the Project can be analyzed from three perspectives: the project's aim, method and the composition of the participants. Unlike its predecessors, the Project distinguished itself in its aim to discover the legal principles shared by major legal systems in the field of contracts law. Such an aim is cosmopolitan in nature, in the sense that it aimed to break down traditionally perceived boundaries between legal systems and penetrate the existing prejudice with respect to their similarities and differences. In achieving this aim, the Project not only invented a 'factual' method to examine the legal solutions offered by different legal systems to similar legal problems in order to avoid parochialism, but also convened a group of legal scholars who were either born in, or highly acquainted with, the legal systems under study.

However, shattering parochial perspectives (i.e. bias and prejudice) in comparative law is hardly an easy task. Having affirmed the project's significance, the paper then argues that the project also has limitations, in terms of its methods and aim, that threaten inconspicuously to destroy the cosmopolitan nature of the Project. Moreover, the cosmopolitan ideal of comparative law itself may well encounter the danger of misinterpretation, and one of the consequences of this is to give rise to the kind of 'legal eschatology', i.e. critiquing one legal system solely on the basis of it not possessing certain features and structures of the other system that one admires or idealizes. After describing the danger of 'legal eschatology', the paper concludes by discussing some new methodological developments in the practice of comparative law.

Therefore, the paper is organized as such: Part 2 describes the partialities and biases embedded in existing comparative legal studies, and the consequences of this for the discipline. Part 3 elucidates what I consider to be the 'cosmopolitan' goal of comparative law, and explains the development of this idea's theoretical basis as well as its relationship to the notion of rationality that is expressed in the language of modern comparative law. Part 4 introduces the Cornell Common Core Project and its cosmopolitan goal from three perspectives: its aim, its methods and the composition of its participants. By identifying the advantages offered by the Project to comparative legal methodologies, the paper explicates how other theories fall short of the Project in terms of attaining the cosmopolitan goal of comparative law. Part 5 and Part 6 discuss the limitations of the Cornell Common Core Project inherent to its methodologies and aims, and then the danger of misinterpreting the cosmopolitan goal of comparative law into a kind of legal eschatology. Part 7 briefly introduces some new development in the practice of comparative law at Cornell Law School. 


\section{The Shackle of Partiality and Parochialism in Comparative Law}

Jane Austen once said in Pride and Prejudice, '[v]anity and pride are different things, though the words are often used synonymously. A person may be proud without being vain. Pride relates more to our opinion of ourselves; vanity to what we would have others think of us'. To read this famous saying differently, the difference between pride and vanity underscores the fact that the way that others view a person is not identical to the way in which the person views him or herself. However, which view is more accurate is not easy to tell, because both may be inevitably colored and biased by the individual perspectives of the viewers. On the one hand, an insider of a story is always partial, since his vision is confined by his own role; on the other hand, an outsider does not necessarily see things more clearly even from a distance, since they might be blind in their own muse and deceived by various preconceptions.

An insider's view is often incomplete. For example, the ancient imperial China, during the period of the 'close-door policy' at the end of Qing Dynasty, became increasingly isolated. At that time, the Chinese empire naively believed they were the 'God's favored one' (tina zhi jiao zi) and that they were the rulers of all the lands in the world (si hai zhi nei jie wei huang tu). But, such beliefs are just fantasies created by isolation, and they were disillusioned when the invading troops of the Eight Powers assaulted Beijing and occupied the Summer Palace in 1900. However, an outsider also tends to be narrow-minded. This is because of the insurmountability of factors like personal and emotional preferences, inconstant perspectives and alike, which often come at the expense of distorting the reality. Another important cause of distorted perception applies to both the insiders and outsiders, and that is the fact that reality is constantly changing, but experience is always limited, and thus knowledge becomes out of fashion quickly. Just as what Ray Huang said in China: A Macro History, '[i]n sum, the China that we are dealing with is more a phenomenon under a movement than a settled entity. Robust with energy and never averted from experiment, it is by no means devoid of self-contradictions. We know that the mass has been stirred up, but we are not so sure where it is heading [...] One is likely to be carried away by his first impression and sentiments. ${ }^{17}$ Contrary to the fast changing reality, however, human perception is constantly subject to limitations. Therefore, our reflection upon the reality is inevitably fraught with partiality and tainted views.

${ }^{17}$ Ray Huang, China: A Macro History (1997) 23. 
Given the imperfection of human nature, it is unavoidable that comparative law has to deal with the problem of partiality and parochialism. However, since comparative law is a discipline based mainly on understanding, this problem becomes fatal to it. In Lawrence $v$ Texas, the US Supreme Court Justice Scalia once said, 'this Court [...] should not impose foreign moods, fads, or fashions on Americans.' ${ }^{18}$ On the one hand, from a comparatist's point of view, Justice Scalia's sharp and disdainful tone represents the pervasively parochial mind-set of American legal scholarship. The words, 'impose' and 'foreign', sound irritating to the ears of others. But on the other hand, they do serve as a warning to comparatists of the embarrassment they might face, every time when they try to impose certain foreign values mechanically upon domestic legal practices without first proving the validity of such actions. Put together, these two aspects of Justice Scalia's assertion against foreign elements in the US courtrooms characterise two forms of the perennial problem of parochialism in the field of comparative law: the former denotes the exclusive narrow-mindedness of insiders, while the latter points out the self-centeredness of outsiders.

Such parochialism significantly undermines the vitality and integrity of comparative law. As has already been explained, an indispensable part of what comparatists do is to seek proper ways to understand one or more legal systems different than their own. In this sense, the seemingly incurable problem of parochialism has essentially become an Achilles' heel of comparatists in general, and even the works of the greatest comparatists could be jeopardized by the evil it generates.

Dating back to the Enlightenment period, Montesquieu's remarkable and classic work, The Spirits of The Laws, describes the peculiarity of law and society and he thereby set a pessimistic tone for comparative law. His famous saying goes like this:

They (the laws of a country) should be relative to the nature and principle of the actual, or intended government; whether they form this principle, as in the café of political laws, or whether they support it, as may be said of civil institutions. They should be relative to the climate [...] they should have a relation to the degree of liberty which the constitution will bear; to the religion of the inhabitants, to their inclinations, riches, number, commerce, manners, and customs, as also with their origin, with the object of the legislator, and with the

${ }_{18}$ Lawrence $v$ Texas, 123 S Ct 2472, 2495 (2003). 
order of things on which they are established, in all which different lights they ought to be considered $[. . .]^{19}$

But it can be said that now Montesquieu's assertions can no longer be justifiably applied to comparative law. ${ }^{20}$ The narrow-minded relativism embedded in his assertions is unwelcome in modern comparative law. For example, Montesquieu spilled much of his ink in deriding Chinese government and society as what he called 'despotic' ${ }^{21}$. Such a definition, regardless of how justified it can be, is nevertheless made in an intrinsically prejudiced manner, since his interest in China is purposefully related to his concern for European and French politics. $^{22}$ Moreover, Montesquieu's disdain for values, such as virtues and social manners, which were traditionally cherished by the ancient Chinese society, emanated from his personal preference on liberty, individual initiative, and political virtues such as separation of powers. Thus, how Montesquieu characterised Chinese society and Europe reflects what they looked like to him. His characterisation of Chinese society appears to be parochial in the sense that it makes it difficult for him to appreciate the important role played by various social mechanisms in ancient China outside of the legal sphere, and in this way the value of his comparative work is greatly reduced.

Let me add another example. John Dawson's ambitious comparative work, The Oracles of The Law, serves as an excellent example of how modern comparatists' work could influence and reshape people's understanding of others' and even their own legal systems. ${ }^{23}$ In Dawson's case, it is Dawson, the American comparatist, whose work was so fundamental and influential that it shaped the way that the French themselves thought of the French legal system. ${ }^{24}$ In his book, Dawson's work successfully produced an enduring, powerful and stereotypical portrayal of a strictly formalist French legal system. And this image has domi-

${ }^{19} \mathrm{C}$ Montesquieu, 1 The Spirits of The Laws. Translated from the French of $M$. de Secondat, Baron de Montesquieu (1794) <http://find.galegroup.com/ecco/infomark.do?\&source=gale\&pro$\mathrm{dId}=$ ECCO\&userGroupName $=$ cornell\&tabID =T001\&docId=CW3324479092\&type =multipage \&contentSet=ECCOArticles\&version=1.0\&docLevel=FASCIMILE $>$ [accessed on 1 March $12014]$.

${ }^{20}$ See Riles, above n 13,16 .

${ }^{21}$ See Montesquieu, above n 19, 396.

${ }^{22}$ See Simon Kow, 'The Idea of China in Modern Political Thought: Leibniz and Montesquieu' (2005) <http://www.cpsa-acsp.ca/papers-2005/kow.pdf> [accessed 12 March 2014].

${ }^{23}$ This is an example of the phenomenon that Professor Annelise Riles called 'the network inside out'; see generally: A Riles, The Network Inside Out (2000).

${ }^{24}$ See M Rheinstein, 1 Collected Works (1979) 88-9. 
nated both the French and American legal minds ever since Dawson's work came out. $^{25}$

Having emphasised the formalist aspect of the French legal system, Dawson's characterisation of the French judiciary as opposed to the American one appeared to be single-dimensional and unilateral. According to Dawson, the French judiciary functions stagnantly: given its complete civil law tradition, which bases the entire legal system completely on written civil laws, the French judicial system operates in a purely instrumental way and acts as an organ, which mechanically applies legislative texts to real cases. However, as Professor Mitchel Lasser points out in his analysis of Dawson's comparative work, such a description hardly represents the complete picture of the French judiciary, since in reality it operates on two different dimensions: it does not operate only on an 'official' dimension, but also on an 'unofficial' one. What's problematic is that the latter dimension has long remained unnoticed by traditional studies. ${ }^{26}$

The parochialism embedded in Dawson's portrayal of the French judicial system corresponds to his parochial and incomplete vision; however immense and extensive his knowledge and observations are, he couldn't produce a more complete description of the French legal system without keeping a cosmopolitan goal in mind. The consequence of Dawson's parochialism is the distortion of both the author's and the readers' understanding of that classic system. Lasser explains, the stereotypical and prevailing 'official' portrait of the French courts, represented by Dawson's theory, constitutes a 'skewed account' of them, ${ }^{27}$ and it 'masks' ${ }^{28}$ the fact that French judiciary, in some way, does operate as effectively as its American common law counterpart, i.e. through a 'hermeneutic' mode of interpretation of the French codes, which requires French judges to interpret the Code in terms of sociopolitical theories that are extrinsic to the Code's grammar.'29

The parochialism embedded in Dawson's work can also be attributed firstly to the influence of the then prevailing legal discourse in the United States, i.e. American legal realism, and then to Dawson's common law-centric ideology. ${ }^{30}$ By describing the French jurisprudence as rigid and formalistic, and the French

\footnotetext{
${ }^{25}$ See Mitchel Lasser, 'Judicial (Self-) Portraits: Judicial Discourse in the French Legal System' (1995) 104 Yale LJ 1325, 1326.

${ }^{26}$ Ibid, 1329.

${ }^{27} \mathrm{Ibid}, 1326$.

${ }^{28}$ Ibid, 1327.

${ }^{29}$ Ibid, 1328.

${ }^{30}$ Ibid, generally.
} 
courts as a 'distrustful', 'instrumental,', 'parsimonious ${ }^{33}$ and 'subordinate ${ }^{34}$ organ, whose sole job is to mechanically apply written codes, Dawson concludes that the operation of the French legal system severely hampers the development of a pragmatic American style case-law system. Dawson's obstinate attitude towards the French judicial system emanated from his self-centered common-law background, which is completely incompatible with the civil law tradition. Such a mentality expressed in his comparison of the French judiciary to the American one can be summarized as a 'whatever-is-different-is-bad' mindset, which has fundamentally undermined the quality of understanding in previous comparative works. ${ }^{35}$ To use Professor Reimann's words, this is a kind of 'arrogance ${ }^{36}$ that often presides in comparative scholars' minds.

The kind of standing one takes in favor of the features resembling those of his own system as displayed in Dawson's work hardly exists only among American comparatists, because to some extent, one's conception of law is significantly shaped by one's legal background and will inevitably be incorporated into one's judgment on any legal system. For example, According to Professor Vivian Curran, the criticism of American legal realists made by the prestigious German legal theorist, Kantorowicz, reflects his personal conception of law, which is civilian in nature. ${ }^{37}$ Kantorowicz saw more value in the objectivity and systematization of a legal system than in its ability to focus on facts. Such a preference reveals a deep influence of the civil law tradition to his understanding of law.

Similarly, conflicting ideas sometimes best serve to exemplify how understanding can be coloured by tainted eyes. For example, in traditional Chinese society, the official law only regulated criminal actions, whereas customary laws dealt with what we now think of as civil law issues. Regarding the nature of these

\footnotetext{
${ }^{31} \mathrm{~J}$ P Dawson, The Oracles of The Law (1968) 376.

32 Ibid, 411.

${ }^{33}$ Ibid, 411

34 Ibid, 378 .

${ }^{35}$ According to Lasser, the same applies to John Merryman's characterization of the French judicial system, as Merryman used terms like 'interpretation', 'very much like judge-made law' and concluded that ' $\mathrm{t}$ ] he principle that judges cannot make law had many other implications', see, Mitchel Lasser, 'Comparative Readings of Roscoe Pound's Jurisprudence' (2002) 50 AJCL 719, 720-1.

${ }^{36}$ P G Monateri, Methods of Comparative Law (2012) 89.

${ }^{37}$ See generally V G Curran, 'Rethinking Hermann Kantorowicz: Free Law, American Legal Realism and the Legacy of Anti-Formalism', in A Riles (ed), Rethinking The Masters of Comparative Law (2001) 66, 66-91.
} 
customary laws in ancient China, there have been disagreements between Western scholars and Chinese scholars: whereas the former, such as Professor William P Alford, argued that the imperial Chinese government did have the authority over civil law matters and local customs functioned as a tool of the government to exercise this authority, Chinese scholars, e.g., Liang Zhiping, insisted that such a conception of custom laws was traditionally inconsistent with Chinese culture, according to which the notion of law referred particularly to penal laws, and there was no such a thing as civil law in ancient Chinese society as understood in the West. $^{38}$

In short, to understand a foreign legal culture is difficult, particularly when the observer is severely biased by preconceptions; nevertheless, the danger of parochialism produced as a result of such biases is always lurking in comparative law. However, this fact does not mean that achieving genuine understanding and appreciation of different legal systems is entirely impossible. On the contrary, through diligent learning of and 'immersing' themselves in different legal cultures, comparatists can obtain a high degree of understanding and knowledge of the legal systems they study. However, to do this, it is essential for comparatists to possess a kind of professional spirit, i.e. a cosmopolitan spirit, which helps keep them alert of the danger of being biased and encourages them to develop knowledge and methods that are capable of avoiding parochial views. Otherwise, comparative law will always be haunted by the shadow of parochialism.

\section{The Cosmopolitan Goal of Comparative Law}

This paper therefore argues that comparative law should establish a paramount goal of cosmopolitanism, according to which comparatists should always bear in mind that the goal of their work is to seek genuine understanding of different legal systems and to try to avoid distorting their understanding by biases and prejudice embedded in their perceptions. This requires them to understand a foreign legal system from the perspectives of the people who live in there, and not from their own perspectives. For comparative studies, how the local people think of their own legal system is more important than what the system looks like in the comparatists' eyes.

\footnotetext{
${ }^{38}$ See generally: William P Alford, To Steal a Book is an Elegant Offence: Intellectual Property Law in Chinese Civilisation (1995); and Liang Zhiping, The Pursuit of Harmony in Natural Orders: A Study on Chinese Traditional Legal Culture (1997) 249.
} 
But, as already recognized, no one is perfect and parochialism is a fault deeply inherited in human nature. Thus, what this paper argues is that comparatists need to first be sober of the tendency towards bias and then keep on working toward the cosmopolitan goal; how much they could achieve is another question. It may be better to call such spirit an 'ideal' rather than a 'goal'. However, the author prefers the word 'goal', since an 'ideal' may seem so impossible that it discourages people from pursuing it. Having a cosmopolitan goal is more like a kind of professionalism for comparatists than a delusional vexation. According to this goal, it is the job of comparatists to remain critical to both their and others' works and act actively against parochialism.

It should be noted in the first place that the idea of 'cosmopolitanism' is hardly a novel one. It originated from the Greek and Roman philosophies. Later, Immanuel Kant introduced this concept to comparative law. In his Perpetual Peace, Kant advocated the 'cosmopolitan right', the right of an alien not to be treated as an enemy upon his arrival in another country. Such a right is based on the logic that people belong to the same global community so they cannot treat each other unfairly. Moreover, to respect the cosmopolitan right, people have to use 'reasons'; thus, those, who could be hospitable and tolerant to people from outside of their community, are called 'rational' beings. It follows that, underlying Kant's construction of the cosmopolitan right, there is a link between cosmopolitanism and rationality: the latter is the means, whereas the former is the end.

The relationship between cosmopolitanism and rationality is further elaborated by Max Weber, who contends that understanding, or verstehen, is the proper way to study social phenomena and 'hermeneutics' is a good tool for this purpose. Weber believes social actions can be classified into four ideal types: meansends rational action, value-rational action, affectual action, and traditional action. He thinks while values play important roles in understanding social actions, they must be kept outside of researchers' interpretations of these actions. Weber's idea of rationality in social science adds tremendous value to comparative law, since it urges comparatists to avoid the tendency towards bias and prejudice. To study a foreign legal system, one is inevitably inclined to impose his own conception of law in his study of it, or to use his own preference to judge it. Rationality, however, tells him to overcome the influence of individual perspectives. ${ }^{39}$ Rationalism also encourages comparatists to flush out old and canonical ideas and to emancipate their minds from the fetter of stereotypes. It is amazing to see how Weber himself disregarded the traditionally perceived boundaries of national states in search of

\footnotetext{
${ }^{39}$ See Riles, above $\mathrm{n} 13,16$.
} 
formalism and rationalism.

Having said that, it is easy to understand why rationality has become the precept of modern comparative law-by taking into account the meanings that actors attribute to their own actions, comparatists put themselves in other peoples' positions in order to understand them. In this way, comparatists do not need to turn on personal preferences and emotions, and they could, thereby, be unaffected by individual perspectives and reflect a foreign legal system unbiasedly. However, even rationality cannot resist the tendency towards biases and prejudices. As in Weber's case, rationality is undermined by his pursuit of formal rationalism. Weber sought to establish formal rationalism as the ultimate destination of both social and legal reasons but such efforts were made at the expense of sacrificing objectivity and 'historicity. ${ }^{40}$ Thus, viewed from this lens, rationality displays itself in a very instrumental fashion; if comparatists insist solely upon this doctrine, they then run the risk of creating a new kind of parochialism masked by the irrationality hidden under the superficial name of 'rationality'.

Therefore, although comparative law benefits greatly from rationality, it nevertheless fails to completely get rid of parochialism and often deceives people about its existence. No wonder comparatists frequently express their concern about the state of comparative law: '[i]nstead, comparatists, unable to escape the 'system' into which they were institutionalized, have simply projected onto the international scene the positivism that they were used to practicing within their own law, ${ }^{41}$ and 'then she (the comparatist) cannot walk away from her own situatedness. ${ }^{42}$

Given the limitations of rationality, this paper argues that comparatists should elucidate the cosmopolitan goal (or tenant, precept, ideal) of comparative law. Recognizing the difficulty of arriving at such a goal does not, and should not, stop comparatists from pursuing genuine understanding, nor should it dampen their enthusiasm in seeking such understanding. Looking back, comparative law has achieved remarkable development both in terms of the scope of legal systems under study and in terms of the maturity/diversity of the methodologies it has employed. As the world becomes more integrated and states more interactive, both opportunities and demands for cultural exchanges are aggrandized. Under such a context, genuine understanding is becoming increasingly possible. To

\footnotetext{
${ }^{40}$ See Otto B Van Der Sprenkel, 'Max Weber on China' (1964) 3 Hist \& Theory 348, 351.

${ }^{41}$ Pierre Legrand, 'Siting Foreign Law: How Derrida Can Help' (2011) 21 Duke JCIL 595, 598.

${ }^{42}$ Mitchel Lasser, 'The Question of Understanding, in P Legrand and R Munday (eds), Comparative Legal Studies: Traditions and Transitions (2003) 197, 219.
} 
reiterate Riles's words, '[w]e are far away, by now, from Montesquieu's assertion that the law suitable to one people is probably not suitable to another ${ }^{2}$.

\section{The Cornell Common Core Project and Its Cosmopolitan Goal}

The Cornell Common Core Project was a huge comparative work conducted in the 1960s at Cornell Law School under the leadership of Professor Rudolf B Schlesinger. It sought to examine the similarities and differences in the law of contracts in major legal systems, including the American and English legal systems, the common law systems in other countries, and the civil law systems in countries such as France, Germany, Switzerland and Italy, as well as some socialist legal systems and the legal system in South Africa.

At the first sight, the project looks like a normal comparative contracts law study, which attempts to examine the differences and similarities in contracts law among different legal systems, albeit a large-scale one. What has not been noticed, or at least not explicitly pointed out, however, is that the project distinguishes itself from other comparative studies by the cosmopolitan goal embodied in its methods of study. The innovative 'fact-oriented' questionnaire method combined with the intellectually collaborative approach that the project used in the course of study contributed significantly to comparative law and its methodological pool, because they are apt to get over the individual perspectives that predispose comparatists to work with parochial views.

The Project's primary purpose is to '[ascertain] [...] the extent to which there exists common ground, or a common core, among a major portion of the world's legal systems. ${ }^{\prime 4}$ To describe it in a more instructive way, they wanted to discover whether or not there are common cores of law existing among the world's major legal systems and if so, what are they. To search for the common cores, their entry point is contracts law, which has similarities that seemed easier to detect.

However, by defining this purpose, they did not intend to discover only similarities while ignoring or denying the existence of differences in these legal systems. Rather, the aim was to 'discover'-different from mere 'description' and not amounting to 'constructing' or 'reinventing' something that was not actually there-the existence of the common core in multiple legal systems. As

\footnotetext{
${ }^{43}$ See Riles, above $\mathrm{n} 13,16$.

${ }^{44}$ R B Schlesinger (ed), 1 Formation of The Contracts: A Study of the Common Core of Legal Systems (1968) 2.
} 
Schlensinger puts it, the project was all about 'identification' and 'formulation' of 'elements of similarity as well as dissimilarity'. ${ }^{45}$

To express it in another way, there was no presupposition that these common grounds did, or must, exist, and the Project tried to be open to the discovery of both similarities and differences without bias. The gist of the word, 'discover', is that the project sought to conduct 'true comparison', ${ }^{46}$ which is to obtain deeper understanding than previous works did, and it did so by distinguishing its approach from mere 'compilation' and 'juxtaposition. ${ }^{47}$ Thus, the aim of the Project is in nature cosmopolitan in at least two senses: on the one hand, it seeks to transcend the borders between different legal systems, which were traditionally regarded as 'impenetrable'; on the other hand, it emphasises the need to eradicate preconceptions and biases.

In essence, the project consequentially re-defines and revives the normative nature of comparative law as a discipline of true comparison. Moreover, the participants in the project astonishingly exhibited a high degree of awareness and cautiousness of the danger of being biased and parochial: 'the similarities and dissimilarities often are so obvious to trained eye that mere juxtaposition becomes an implicit comparison; indeed, mere description of a foreign approach of several legal systems may sometimes imply a comparison with certain elements in the reader's own legal system'. ${ }^{48}$ Such struggles against presupposition and superficiality can be found throughout the course of the study, as described by Schlensinger, 'the participants in the Cornell Project asked themselves the agonizing question often prompted by social science research: did we merely demonstrate the obvious? 49

Admittedly, awareness and cautiousness do not always work to eliminate biases; apparently knowing this, the project employed methods that are especially effective in reducing individual perspectives, i.e. the factual method and the teamwork method.

On the one hand, the project is an intellectually collaborative work undertaken by a group of lawyers from different legal backgrounds and with diverse knowledge. Each of the participants chosen were 'thoroughly familiar with doctrine and practice in one or more of the legal systems chosen. ${ }^{50}$ Given the lim-

\footnotetext{
${ }^{45}$ Ibid, 3.

${ }^{46}$ Ibid, 2 (emphasis added).

${ }^{47}$ Ibid.

${ }^{48}$ Ibid, (emphasis added).

${ }^{49}$ Ibid, 41.

${ }^{50}$ Ibid, 30 .
} 
itation of individual perspectives as well as the tendency of human nature to be biased, and the collaborative nature of this project was apparently the result of a highly conscious and intentional action of design aiming to avoid parochialism:

Whoever undertakes multilateral comparative research must adjust his methods to a fundamental and unalterable fact: that no single human being, however learned, possesses enough knowledge of diverse legal systems to assemble and correctly to understand all of the theoretical and practical information on national laws which forms the necessary raw material for comparison. Teamwork of a number of lawyers, each of whom must be thoroughly familiar with doctrine and practice in one or more of the legal systems chosen, thus seems to be indispensable. ${ }^{51}$

It is now necessary to take a closer look at the composition of the research team. Specifically, it was composed of: Ishwar Chandra Saxena, Dean of the Faculty of Law, University of Rajasthan, who is responsible for the writing of the English reports, Johannes Leyser, Dr jur in Freiburg and LLB and Reader in Comparative Law and Public International Law at the University of Melbourne, for the Annotations on Australian-Canadian-New Zealand Law and the English-Australian-Canadian-New Zealand Reports and South African Reports, W J Wagner, LLM in Warsaw and dr en Droit in Paris, SJD from Northwestern Law School, and then Professor of Law at Indiana University, for Communist Legal Systems Annotations and Polish Reports and Annotations, I R Macneil, Professor at Cornell Law School, and R B Schlesinger, Professor at Cornell Law School, for the American Reports, P Bonnassies, Professor of Law at the Law Faculty of the University of Aix-Marseille, for the French Reports, K $\mathrm{H}$ Neumayer, Professor of Law at the Universities of Lausanne, Switzerland, and Würzburg, Germany, for the German-Swiss Reports with Austrian Annotations, G Gorla, Professor of Law at the University of Rome, Italy and Professor-at-Large at Cornell University, for the Italian Reports and Annotations, and W Lorenz, Professor of Law at Cornell University, for the Austrian-German-Swiss Reports.

The process of the teamwork was rather prolonged. It took ten years for them to come up with the final Individual National Reports and General Reports. In doing the teamwork, each participant first received a set of Working Papers, which contained the same questions asking about the legal

${ }^{51}$ Ibid. 
positions of legal systems covered with respect to a similar set of factual issues described thereof. Participants then drafted their own Individual/National Reports and Annotations, explaining the legal positions of the legal systems that they represented, in response to the Working Papers. After collecting all individual reports, the participants together contributed to the compilation of the General Reports, which analysed the results of their findings. Each participant was, therefore, individually responsible for the national reports and annotations, but they bore joint responsibility for the general reports.

The diverse background of the participants enabled the project to come up with a cosmopolitan view of the subject under study. Through oral discussions and meeting, the participants exchanged ideas and perspectives that supplemented each other's view by supplying knowledge of different legal systems and different conceptions of law. Thus, the result of their collective work was in nature a multi-lateral comparison. This is in accordance with the aim of the project, which was to obtain and verify a high degree of 'multinational validity'.

More importantly, although not explicitly indicated, the research of the participants was not restricted to the 'formal' rules of contracts in their legal systems. Granted, the subject of contracts law implies that the major part of the research was on a bunch of formal laws, i.e. the contracts law or commercial code, and cases and judgments. However, in the course of study, the researches also examined 'informal' laws/rules, which influence contractual behavior either in the case of legal vacancy or as supplement to formal laws. For example, in the absence of legal authorities concerning the legal status of contracts in self-service enterprises, there was generally a lack of both statutory and judicial authorities, so most researchers referred to relevant legal literature to determine the situations of their legal systems, including the opinions stated in the notes attached to specific legal provisions. Based on such literature, for example, Neumayer concluded that in German ' $t$ ] he view prevails that the customer makes his offer at the cash register, and that the cashier accepts it on behalf of the storekeeper. ${ }^{53}$ Such references to the informal source can be found in many other places. ${ }^{54}$ Also, when participants engaged in legal analysis, they sometimes inevitably incorporated their own experience in and knowledge of particular cultural and societal background into their research. ${ }^{55}$

\footnotetext{
52 Ibid, 3.

53 Ibid, 373.

${ }^{54}$ Ibid, 334 \& 387.

${ }^{55}$ See e.g. ibid, 338-9 \& 382; See also above nn $47 \& 48$.
} 
Given the huge number of legal systems covered as well as the complexity of the legal and social structures underlying the legal issues under study, the collaboration of a group of lawyers, who were well acquainted with the legal systems covered, appears to be utterly important. One should be informed that legal phenomena are not isolated but inter-connected with each other in systematic ways. Knowing a part is not knowing the whole. This reality necessitates the kind of intellectual collaborations in the Project to be conducted in comparative law. Thus, by requiring collective investigations and group discussions, the teamwork method is the only way to collect knowledge of each legal system under study that can go beyond the individual lenses of the comparatists. This explains why Schlesinger was so decisive and confident, when he said that 'teamwork of a number of lawyers [...] thus seems to be indispensable for comparative studies' ${ }^{56}$

In addition to the teamwork method, the Project takes pride in its 'factoriented questionnaire method', which has often been applauded by later comparatists. ${ }^{57}$ In order to reconcile the inconsistencies embodied in the legal systems covered, especially in their legal treatments of particular legal issues, e.g. whether a particular issue has legal relevance or is justiciable in a country's court, or whether a scheme is conceived as a legal system, the Project invented the 'factual' approach ${ }^{58}$.

At first, the participants received the same set of Working Papers, which contained contracts cases with detailed factual descriptions. ${ }^{59}$ Each of them then set out to conduct investigations in the legal system assigned to him and then explained the legal positions of that legal system in National Reports. In doing this, they had to pinpoint not only the specific legal authorities supporting their legal positions, but also legal remedies corresponding to them. ${ }^{60}$ Then, the National Reports were gathered together, and all of them sat together to discuss and clarify the positions in their reports. For each oral discussion, there was a

\footnotetext{
${ }^{56}$ See Schlesinger, above $\mathrm{n} 50$.

${ }^{57}$ See Ugo Mattei and Mauro Bussani, 'The Common Core Approach To The European Private Law' (1997-1998) 3 Columbia JEL 339-56.

${ }^{58}$ See Schlesinger, above $\mathrm{n} 44,30-3$.

${ }^{59}$ These cases were selected from judgments in various states, but mainly from common law countries, as a practical matter.

${ }^{60}$ Questions to be answered by participants in their reports included: 'How would the legal system or systems covered by you react to this fact situation? Would the court hold in favor of the plaintiff or the defendant? If for the plaintiff, what would be the kind and measure of relief awarded to him? What are the authorities supporting your conclusion, and what is its doctrinal basis?' See Schlesinger, above n 44, 32.
} 
general reporter to present the result of the collective work: the similarities and dissimilarities thereof. And they then came up with the General Reports based on these results.

Furthermore, to ensure that each participant dealt with the same facts, individual reports were labeled with specific symbols, such as A1, A2 and B2, and these symbols identified the subjects under consideration. In this way, "[a]11 of the Individual reports bearing the symbol A-3 deal with the same subject as the General Report on A-3; all these Individual Reports appear together, in the alphabetical order', ${ }^{61}$ and 'within each individual report, again the same organizational scheme is adopted as in the related General Report. Thus, subsection II G of the French Report on B-5 deals with the same subtopic as the corresponding sub-section of the General Report on B-5, ${ }^{2}$

The factual approach was designed to avoid conflicting situations, in which a legal issue has different legal implications in different countries. For example, many issues that are regulated by law in one legal system have no legal relevance in the other. Thus, by framing the question in factual terms, the working papers were not designed in the presupposition of legal relevancy under any of these legal systems. Also, the factual approach opened doors to both formal and informal rules. By formulating questions in factual terms, the Working Papers did not confine the scope of answers to the formal dimension of a legal system. Rather, they allowed the comparatists to pursue the genuine knowledge of the legal systems concerned beyond their formal sphere.

In addition to the way the factual approach avoided biases towards a particular legal system, as Giovanni E Longo, Professor of Law at Rome and one of the participants, later recalled, the factual approach was actually operated in an even more complex way. He gave an example of how the factual approach solved the problem concerning the different legal treatments of the 'effects of "an agreement contemplating a writing", 63 In that case, because the civilians took into consideration a different element in determining whether or not a pre-contractual oral agreement should be binding on the parties, i.e. the civilians relied on the purposes of the contractual parties, and this element was absent in other legal systems, they further divided the fact into two sub-parts, each containing a different hypothesis regarding the parties' intention.

\footnotetext{
${ }^{61}$ Ibid, 60.

${ }^{62}$ Ibid.

${ }^{63}$ Giovanni E Longo, 'The Cornell Project on the Common Core of Legal Systems: Views of a Civilian' (1965-1966) 4 Columbia JTL 1, 6.
} 
The factual questionnaire method, thus, enabled the Project to discover the existence of agreements and disagreements underlying the various legal systems under study without biases and parochial views. It also facilitated cultural exchange and communication. As Schlesinger stated in the beginning, "ii]t was clear from the outset that these questions had to be formulated in such a way that our colleague from India would understand them in the same way as our colleague from Italy. If the questions had been asked in abstract legal terms, each participant might have read particular notions of his own legal system into such terms, and the result would have been the complete lack of a common focus' ${ }^{64}$

The combination of the teamwork method and the factual approach in the Project thus was an extraordinary methodological invention in comparative law history, and it generated enormous inspirations to future comparative legal studies. As already mentioned, over time, every piece of great comparative work cannot resist the subjectivity of the individual lens and preferences of the authors. That is one of the reasons why David Kennedy concluded that comparative law has its own politics. ${ }^{65}$ However, by permitting the collaboration of individuals and the exchange of their perspectives, the Project enabled the compensation for the limitations of their views; and by replacing legal terms with factual terms, it made sure that everyone was on the same ground before they started out understanding. As Sacco later acknowledged, 'I observed that Schlesinger had approached those misleading circumstances that the superficial comparatist neglects (different mentalities, different, tacit assumptions) and has found the correct procedure to overcome them' ${ }^{66}$ The groundbreaking method of the Project made a great start for comparative legal studies to pursue the cosmopolitan goal.

The project generated enormous influence upon later studies. Ugo Mattei and Mausino Bruno were inspired by the Project and they later set out to carry out their own 'common core' project on European Private Law. It is said that the two authors 'stood on the shoulder of the giant, Rudolf Schlesinger'. ${ }^{67}$ Rudolfo Sacoo supplemented the common core project by subsequently formulating the theory of 'legal formants'. Schlesinger and Sacco together are called 'the unquestioned

\footnotetext{
${ }^{64}$ See Schlesinger, above $\mathrm{n} 44,31$.

${ }^{65}$ See generally: David Kennedy, 'On The Methods and Politics of Comparative Law', in P Legrand \& R Munday (eds), Comparative Legal Studies: Traditions and Transitions (2003) 345.

${ }^{66}$ Ugo Mattei, 'The Comparative Jurisprudence of Schlensinger and Sacco', in A Riles (ed), Rethinking The Masters of Comparative Law (2001) 238, 251.

${ }^{67}$ Vivian G Curran, 'On The Shoulders of Schlensinger: The Trento Common Core of European Private Law Project' (2002) 2 GlobalJurist Frontiers 1, 1.
} 
methodological and theoretical godfathers of the Common Core Project. ${ }^{68}$ In fact, Schlesinger has foreseen such a huge influence, and he hopes that the project has the potential to benefit a variety of legal activities, including professional education and national and international legislations. ${ }^{69}$ But such a pragmatic nature of the Project does not in any way undermine the extraordinary methods that it employed in pursuing cosmopolitan understanding.

In short, the cosmopolitan aim and methods of the Project deserve to be re-accounted and re-addressed at the present time, when comparative law is still in search of proper ways to understand various legal systems. In terms of its groundbreaking innovation in methods, the Project serves as an incomparable inspiration for future comparative legal studies to pursue cosmopolitan understandings.

Also, the Project deserves extra credit, since it stood independent from the parochial debates engaged in by previous comparatists, and it remained exceptionally sober-minded during its own time. Given the historical background of the Project, it's surprising to find that the Project retained its integrity in the midst of competing American legal discourses: legal realism, anti-formalism, and law and sociology, and so on. Specifically, the project was undertaken during a period when comparative law practices on both sides of the Atlantic had to fight against the realist-inspired conceptions and methodologies. Legal realism was so dominant in American legal thought that many assumptions were taken for granted in comparative legal studies by comparatists in the United States. European comparative law, sometimes, defended their legal theories against the assaults made by American scholars. So, the result was that both sides ended up dealing with the parochial views caused by each other's indigenous legal discourse.

Such struggles could be exemplified, on the American side, by Dawson and Merryman, as previously discussed, both reflecting a mindset that law is 'meaningful only when located in the total context in which they are being used-in the community process in which people are using these doctrines to effect, or justify, some specific distribution of values ${ }^{70}$; on the Continental side, by Kantorowicz's defense for his 'free law' theory, previously mentioned, too, which criticized the American realists of denying the positive form of law. ${ }^{71}$

\footnotetext{
${ }^{68}$ Monateri, above n 36, 124.

${ }^{69}$ Schlesinger, above n 44, 5-11.

${ }^{70}$ Myres S McDougal, 'The Law School of the Future: From Legal Realism to Policy Science in the World Community' (1947) 56 Yale LJ 1345, 1345.

${ }^{71}$ However, some attributed Kantorowicz's critique on American legal realism to his civilian background: see generally above n 37 .
} 
It should be noted that other attempts at searching for new methodologies in American comparative law have also been made. They were all successful comparative projects in one way or another, but neither of them surpassed the Cornell Common Core Project in terms of the methodology that is up to the cosmopolitan standard. For example, Roscoe Pound and Mirjan R. Damaska both tried to transcend the boundaries of legal families or legal systems traditionally laid down by comparatists: the former sought to search for the ideal elements $^{, 72}$ underlying all legal systems, where the latter wanted to formulate a new taxonomy of 'justice and state authority. ${ }^{73}$ Nevertheless, these two figures' giant works could hardly be replicated, since they relied too much on the 'cosmopolitan erudition"74 of the comparatists. Zweigert and Körz developed the functional approach of comparative law in An Introduction to Comparative Law. This approach has exerted fundamental influence upon the methods of comparative law, and it fits the cosmopolitan end of comparative law in the sense that it stimulates deep social inquiries in comparative legal studies. But, its proposition of functionality presupposes the existence of functional equivalences in different societies, and it's influence on comparative law stays only on the micro-level. ${ }^{75}$ The legal historian, Alan Watson, in developing his legal transplants theory, displayed so much optimism that many questioned whether it was realistic enough. The optimistic mood of this theory might mislead the comparative legal studies in some way or another into the celestial bliss. In comparison, the Project really provided the discipline with a groundbreaking methodology that moves it closer towards its cosmopolitan goal.

\section{A Captious Assessment of the Cornell Common Core Project and Its Limitations}

The Project, as already explained, selected participants, who were 'qualified' to represent the legal positions of particular legal systems. Such a qualification was based on the fact that all participants had 'insiders' knowledge' of the legal systems under study. Such an insider's knowledge was obtained either

\footnotetext{
${ }^{72}$ See generally: R Pound, The Ideal Element in Law (1958, reprinted 2002) <http://oll.libertyfund.org/titles/671> [accessed 10 February 2014].

${ }^{73}$ See generally: M R Damaska, The Faces of Justice and State Authority (1991).

${ }^{74}$ See Lasser, above n $35,727$.

${ }^{75}$ See Ralf Michaels, 'The Functional Method Of Comparative Law', in M Reimann \& R Zimmermann (eds), The Oxford Handbook of Comparative Law (2006) 339.
} 
because the participant was born in a society subject to that legal system, or through becoming acquainted with the doctrine, theories and practices of the legal system. The acquaintance of a particular legal system could be achieved by both learning and the so-called 'immersion', which means to study 'not just legal rules but what attaches to them: values, beliefs, traditions and collective memories, understandings, aspirations and emotions. ${ }^{76}$

Nevertheless, the 'insider' approach is problematic. The Project delegated the task of investigations solely to scholars who had the insiders' knowledge; therefore, its result might be tainted by a different set of biases and parochialism, which could be called 'internal biases', or 'internal parochialism'. The existence of such internal biases is hardly deniable, since the way that an insider presents his own legal system depends heavily on his individual conception of law and society as well as the breadth and depth of his knowledge. Also, the significance of internal biases depends on the extent to which his view could represent the general understanding of other insiders. After all, "[d]ifferent Italians will deal differently with the same topic. There is no immaculate perception nor is there such a thing as immaculate representation." ${ }^{\text {, }}$ Thus, it would be wrong to assume that an insider's view reflects the authentic situations in a given legal system: 'prisoners so conditioned do not see the prison any more. ${ }^{78}$

Furthermore, it has been noted that the Project was aimed to discover both similarities and differences among the legal systems under study, so, as the name of the project misleadingly suggests, the Project did not intend to deny the existence of differences across legal systems. It was also stated at the outset of the Project that it was not an effort for legal harmonization, regardless of the effects it has had upon other projects.

However, in spite of its superior methodology, the Project might be similarly influenced by its main author's ideology and preference. As one might already know, the general editor, leader and main organizer of the Project, Rudolf B Schlesinger, was himself explicit about the preference he gave to discovering similarities over differences, and he even forecast that the future of comparative law belonged to the investigation of similarities as opposed to differences. ${ }^{79}$ Such a tendency of seeking commonalities may unfortunately lead to the creation and construction of them.

\footnotetext{
${ }^{76}$ See Curran, above $\mathrm{n} 8$.

${ }^{77}$ See Legrand, above n 3, 54.

${ }^{78}$ Ibid, 181.

${ }^{79}$ See generally Rudolf B Schlesinger, 'The Past and Future of Comparative Law' (1995) 43 AJCL 477.
} 
Thus, if one reads the Project carefully, there might be situations where the General Reports gave favor to similarities rather than differences. A cursory comparison of the General Reports and the Individual Reports gives the reader a hint of the disguised bias towards commonality against differences. In the General Report A-1, for example, it is stated in footnote 2, that it is assumed that the proposal meets the applicable standard of definiteness (see A-3); if it does not, it will not be recognized as an offer. As to cases in which the parties contemplate that their agreement will be reduced to writing or otherwise embodied in a formal document, see C-2, ${ }^{80}$ However, in the American Report A-1, it's pointed out that the decisive language used in this footnote was so absolute and simplified that such a 'dichotomy' of situations might not exist in the judicial practice in the US. ${ }^{81}$

Such an inconsistency between the General Report and an Individual Report, although subtle and well recognised in the book, reveals a desire of the reporter to extract similarities out of the complexity embroiled in multilateral comparisons. And because of the influence of the commonality-inspired comparatists, it is actually in a Project's nature to wrap around and strangle dissimilarities in order to get more evidence of similarities. Such a disguised bias towards similarities silently obscured the existence of differences in different legal systems. The perceived similarities and the obscuration of the existence of differences, therefore, destroy the cosmopolitan nature of the project.

\section{The Danger of Misreading: 'Legal Eschatology' in Comparative Law}

Following the analysis of the cosmopolitan goal of comparative law and the Cornell Common Core Project, the paper argues that there is a danger of turning the legal cosmopolitanism into what the author calls 'legal eschatology. ${ }^{82}$ Serious misinterpretation of the conception of legal cosmopolitanism in comparative law unjustifiably equated it with legal 'assimilation', which may ultimately lead to legal eschatology.

However, the two conceptions are radically different. Legal cosmopolitanism aims at fostering unbiased understanding and appreciation of other legal systems and eliminating prejudice and parochialism in comparative studies; while legal

\footnotetext{
${ }^{80}$ See Schlensinger, above $\mathrm{n} 44,77$.

${ }^{81}$ Ibid, 323.

${ }^{82}$ For example, see generally, Barry Smith, 'Law and Eschatology in Wittgenstein's Early Thought' (1978) 21 Inquiry 425.
} 
eschatology starts from an unjustified presupposition that all legal systems should ultimately move towards a single mode. This ideology of eschatology distinguishes an idealistic world from a realistic world. It creates an idealistic rule of law, typically based on a particular Western legal order that one admires in particular, and then critiques, based on this ideal, a legal system, which departs from this ideal. For example, Chinese legal practices receive frequent critiques from scholars, who honor the Western legal order and values. Their critique of a Chinese legal system is often a 'whatever-is-different-is-bad/ineffective/failed' one.

Legal eschatology leads legal cosmopolitanism astray, because it distorts the situations of the legal systems being critically analysed, and often at the expense of ignoring the importance of local culture and customs. Such an ideology, on the one hand, harms the diversity of legal culture, and on the other hand, creates extremely biased and parochial views. Moreover, it might cause the self-alienation and non-autonomy of legal scholarship and harm the healthy development of the rule of law in the legal system under criticism.

Therefore, legal eschatology is a serious distortion of the concept of cosmopolitanism, which values both unity and diversity. However, such a distortion is a common hazard in comparative law, especially among those comparatists who are unsatisfied with existing legal and institutional arrangements. Comparatists who share the cosmopolitan goal, on the contrary, are able to prevent themselves from making such mistakes. In order not to follow this misunderstanding, comparative studies must be constructed without disrespecting local culture. Identifying the problem to be solved in a particular society in the study before making any comparison is very important, if the researchers still want to take advantage of what they learn from outside, because the same problem might not be found in a different society, and thus, a comparison between the two legal systems will lose its significance. 


\section{Some New Approaches to the Cosmopolitan Goal Developed at Cornell Law School}

American comparative law likes to look back and look forth. ${ }^{83}$ Since 1990s, globalization has led to significant cultural diffusions as well as institutional convergence worldwide. Under this circumstance, comparative law practices have been constantly evolving so as to adapt to the changes of the world. Now, it is attempting to free itself from the dichotomy of international law and domestic law and to develop methodologies that allow comparative studies to transcend the boundaries of space and time.

To understand the implications of such changes in comparative studies, it is necessary to compare past studies with the current ones. Therefore, the paper concludes with a comparison between the Cornell Common Core Project and another comparative project that is currently occurring at Cornell Law School, i.e. the Meridian 180 Program. A practical reason that the paper chooses to make such a comparison is that both projects are initiated at Cornell Law School, both of which contribute to the methodological advancement of comparative law. Moreover, the author is lucky enough to have participated in the latter project as a part-time student research assistant and has witnessed its operation in person. Based on what the author has learnt and considered, both projects provide enlightening ideas for comparatists to produce innovative research methods, and they illuminate the cosmopolitan goal of the discipline. Furthermore, the latter program serves as an improvement of the Cornell Common Core Program, in the sense that its inter-disciplinary and interactive method and transpacific coverage make up for what the Cornell Common Core Project lacks, and all of these three features enhance the ability of comparatists to approach a cosmopolitan understanding.

The Meridian 180 Program is a comparative project under the leadership of Professor Annelise Riles at Cornell Law School and some senior scholars from outside of the law department and even outside of the US. Since its launch in 2012, the project has attracted hundreds of participants. Most of its current members are from the transpacific region, such as China, Japan, Korea, the US and Australia. The aim of the Program is to facilitate a Pan-Pacific dialogue

\footnotetext{
${ }^{83}$ See e.g. Ugo Mattei, 'An Opportunity Not to Be Missed: The Future of Comparative Law in the United States' (1998) 48 AJCL 709; Christopher A Whytock, 'Legal Origins, Functionalism, and the Future of Comparative Law' (2010) 2009 Brigham Young ULR 1879; Clifford Larsen, 'The Future of Comparative Law: Public Legal Systems' (1998) 21 Hastings ICLR 847; Schlesinger, above $\mathrm{n} 79$.
} 
that provides solutions to important regional issues. Those who participate contribute to the diversity and vitality of the Program by mobilising the resources in their knowledge reservoir and introducing their local ethnographical practices to the Pan-Pacific panorama of the Program. The focus of the Program, i.e. the transpacific area, successfully subverts the West-centric, or trans-Atlantic feature of traditional comparative law practices. The Cornell Common Core Project, although trying to be inclusive, sadly falls within the traditional category. Carried out in the 1960s, when cross-transpacific communications were not facilitated and cultural contradiction was significant, the Cornell Common Core Project was constructed mainly as a bridge between the two banks of the Atlantic.

Moreover, it's noteworthy that to call the Meridian 180 Program a comparative 'law' project is not entirely accurate, because the Program is extremely interdisciplinary in nature: not only do its members come from different departments and have different professions-they include renowned legal scholars, anthropologists, lawyers, and economics, etc.-the topics covered also extend widely beyond pure legal issues, from trade issues, financial governance, social movements, environmental issues, cultures and traditions, legal reforms, to political elections and commonwealth issues, etc.

From the perspective of comparative law, the interdisciplinary method employed in the Meridian 180 Program is in accordance with its cosmopolitan goal. Understanding a legal system is impossible, if the observer lacks the knowledge of its legal culture and social tradition. Thus, the diversity of topics and subjects covered by the Program makes it possible for comparatists to have in-depth insights into the indigenous culture of the legal systems discussed. Such an approach resembles what Professor Vivian Curran called the immersion comparison," ${ }^{84}$ which means 'studying not just legal rules but what attaches to them: values, beliefs, traditions and collective memories, understandings, aspirations and emotions. ${ }^{85}$

The Cornell Common Core Project, however, as previously explained, appears to have a tunnel vision: it only sees problems of law from a pure legal perspective, and thus lacks what is the cultural and what is the social. Although the Project also contained a cultural part, ${ }^{86}$ that part was too thin and only ancillary to the legal issues under investigation. Part of this was due to the fact-specific case-study method that the Project employed in the course of study.

\footnotetext{
${ }^{84}$ See Curran, above $\mathrm{n} 8$.

${ }^{85}$ See Cotterrell, above $\mathrm{n} 7$.

${ }^{86}$ As noted above $\mathrm{n} 55$.
} 
While the factual method enabled genuine communication across different legal systems to be carried out, it constrained the scope of the study to pure legal issues. Such lack of sophistication seriously undermines the value of the Project in general. To use Sacco's term, 'legal formants', i.e., the cultural aspect of legal issues, are important, because to know 'only one formant (statute, case, explicit description of a local academic [...])' would be against the cosmopolitan goal of comparative law, and the knowledge obtained thereby 'could not avoid being unilateral and crippled' 87

In addition to the interdisciplinary method, the Meridian 180 Program sets up an extremely interactive online platform for multilateral dialogue. Unlike traditional face-to-face meetings, the members of the Program interact with each other in online discussions. Usually, members put down their comments concerning an active topic on the online forum and then exchange their views with others back and forth, until everyone fully expresses their views. Moreover, every piece of their post is translated into four different languages, i.e., English, Chinese, Japanese and Korean, before being sent to other members to read. In case of disagreement or confusion, members can write new posts in response to each other. In the end, the posts and discussions will be compiled into forum summaries, which will then be published publicly after getting the consensus of each commentator involved. In addition, the Program conducts interviews and organises conferences regularly in the transpacific area, and the reports of these events are posted online as well.

Through translation and communication, the Program enables the elements of languages and technologies to get full play, and once awakened, these elements function to enhance the kind of cross-cultural understanding that is underscored in comparative studies. It has been noticed in the Cornell Common Core Project that since English is not the native language of many participants, there were moments that miscommunication impeded proper understanding. The Meridian 180 Program, however, eliminates the problem of language with the advantages offered by legal translation. Specifically, the Program employs young scholars from different East Asian countries to be responsible for the translation job, and all of them have excellent legal educational background and high linguistic fluency in two or more of the four languages mentioned above. Moreover, as a practical matter, the online tools of the Program further expedite the communication among the geographically dispersed members, whereas inability to show up often caused a member to quit from the Cornell Common Core

\footnotetext{
${ }^{87}$ See Mattei, above n 66.
} 
Project.

In short, comparing the Cornell Common Core Project to the Meridian 180 Program, three points can be made: first, the latter distinguishes itself from traditional comparative studies, including the former, by its transpacific focus, which is no longer West-centric; second, comparative legal studies increasingly call for good interdisciplinary methodologies to enrich the cross-cultural understanding; and third, linguistic and technological tools employed by comparative studies help generate dynamic environments for cross-cultural communications to take place by eliminating cultural obstacles and facilitating inter-regional dialogues. Nevertheless, the pioneering methods invented by the Cornell Common Core Project still have profound implications for comparative studies today, and the awareness of problem-identification reflected in the Project is extremely essential to comparative law. Juxtaposing the two projects, one can surprisingly find that in spite of the fifty-year interval, the Meridian 180 Program still uses the collaborative method as used in the Cornell Common Core Project. This seems to have proved the assertion of Schlesinger that for multilateral comparisons, collaboration seems 'indispensable'. If what remains is always true, then, as Riles said recently with the same tone, " $\mathrm{t}$ ] oday [...] it is not comparison but collaboration that stakes the most powerful claim as a scholarly method' ${ }^{88}$ However, what calls for the collaboration is, in fact, the cosmopolitan goal of comparative studies.

\section{Conclusions}

The invention of the factual method and the teamwork method of the Cornell Common Core Project sheds light on the problem of understanding in comparative law. Given the fact that parochialism is inevitable, comparative law, whose fundamental mission is to obtain genuine understanding across legal systems, should have a cosmopolitan goal. The cosmopolitan goal requires comparatists to pursue understanding of foreign legal systems without biases and prejudices. Such a goal, however difficult to perfectly achieve, has been implied in comparative studies over generations. Rationality, for example, has influenced comparative law to overcome parochialism. However, it cannot eradicate the tendency of comparative studies towards being biased, but it runs the risk of obscuring

${ }^{88}$ See Annelise Riles, 'From Comparison to Collaboration: New Directions in the Ethnography of Law' (Collateral Knowledge, 5 March 2014) <https://blogs.cornell.edu/collateralknowledge/tag/meridian-180/> [accessed 6 March 2014]. 
irrationality in reality. Thus, comparative law should be explicit about its cosmopolitan goal.

The Cornell Common Core Project provides illuminating approaches to the pursuit of cosmopolitan understanding. Both the factual method and the teamwork method invented by the Project suggest more effective ways to overcome individual perspectives in comparative legal studies, especially for comparative projects involving multiple legal systems, languages and cultures. However, the Project is not flawless in terms of how it seeks cosmopolitan understanding, because it limited the scope of its understanding by delegating the jobs to 'insiders' and by driving its orientation towards seeking similarities over differences. The Meridian 180 Program is a new comparative project that is also taking place at Cornell Law School. Compared to the Cornell Common Core Project, the transpacific scope and the inter-disciplinary and interactive method of the Meridian 180 Program promises more possibilities of cosmopolitan understanding for comparative law. Although easily misinterpreted-into legal 'eschatology', for example-the cosmopolitan goal of comparative law should be the primary standard in evaluating methodologies and practices of comparative legal studies. 